\title{
LQR-Based Power Train Control Method Design for Fuel Cell Hybrid Vehicle
}

\author{
Yun Haitao, Zhao Yulan, Liu Zunnian, and Hao Kui \\ School of Automobile and Traffic, Qingdao Technological University, Qingdao 266033, China \\ Correspondence should be addressed to Yun Haitao; yunht@163.com
}

Received 9 September 2013; Revised 13 October 2013; Accepted 24 October 2013

Academic Editor: Wuhong Wang

Copyright ( 2013 Yun Haitao et al. This is an open access article distributed under the Creative Commons Attribution License, which permits unrestricted use, distribution, and reproduction in any medium, provided the original work is properly cited.

Based on the mathematical model of fuel cell hybrid vehicle (FCHV) proposed in our previous study, a multistate feedback control strategy of the hybrid power train is designed based on the linear quadratic regulator (LQR) algorithm. A Kalman Filter (KF) observer is introduced to estimate state of charge (SOC) of the battery firstly, and then a linear quadratic regulator is constructed to compute the state feedback gain matrix of the closed-loop control system. At last, simulation and actual test are utilized to demonstrate this new approach.

\section{Introduction}

Fuel cell vehicle (FCV) is one of the most important trends of new energy vehicles. Since the dynamic response of fuel cell has a property of time lag, which fails to meet the demands of the fast-changing vehicle load, a hybrid power system equipped with auxiliary energy storage device is indispensable. This is so-called fuel cell hybrid vehicle. For such a complex system which has multiple power sources, it is very important for energy management strategy to maintain the power balance of the power train.

There have been many academic papers discussing the energy management of the FCHV in recent years. Hyun et al. [1] discussed the feature of hydrogen FCHV power train based on experimental study. Pede et al. [2] discussed hybrid degree of fuel cell vehicle power train. Mohammadian et al. [3] utilized neural network and genetic algorithm to solve the control problem of the fuel cell power system. Kim and Peng [4] designed a power allocation algorithm based on Markov decision programming (MDP). Eren et al. [5] proposed a control strategy for fuel cell hybrid power system based on fuzzy logic. Ryu et al. [6] designed different energy distribution strategies according to the driving modes of the motor. Torreglosa et al. [7] put forward a power control method based on optimal theory. Recently, there are several patents [8-10] with the focus on configuration and control of FCHV power train. In addition, several research teams pay attention to model and simulation of FCHV [11-14].

\section{Simulation Model of the FCHV Power Train}

The fuel cell hybrid vehicle (FCHV) studied in this research is SHANGHAI prototype vehicle from Shanghai Motor Company, whose power train configuration is shown in Figure 1. The mathematic model of SHANGHAI power train has been constructed based on test data and the equivalent circuit model in our previous research [15].

The following equation is the state-space equation of the mathematic model:

$$
\begin{aligned}
& \dot{x}=A x+B u, \\
& y=C x+D u,
\end{aligned}
$$

where the state vector $\mathbf{x}=\left[\begin{array}{lllll}I_{d c f} & I_{m} & U_{E} & U_{1} & U_{2}\end{array}\right]^{T}$, the input vector $\mathbf{u}=\left[\begin{array}{ll}I_{d c f s e t} & I_{m s e t}\end{array}\right]^{T}$, the output vector $\mathbf{y}=U_{\text {bus }}$, and $A$, $B, C$, and $D$ are the state matrix, as defined in (2), respectively: 


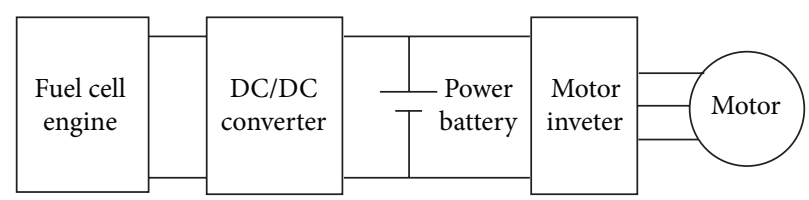

FIgURE 1: Power train configuration of SHANGHAI FCHV.

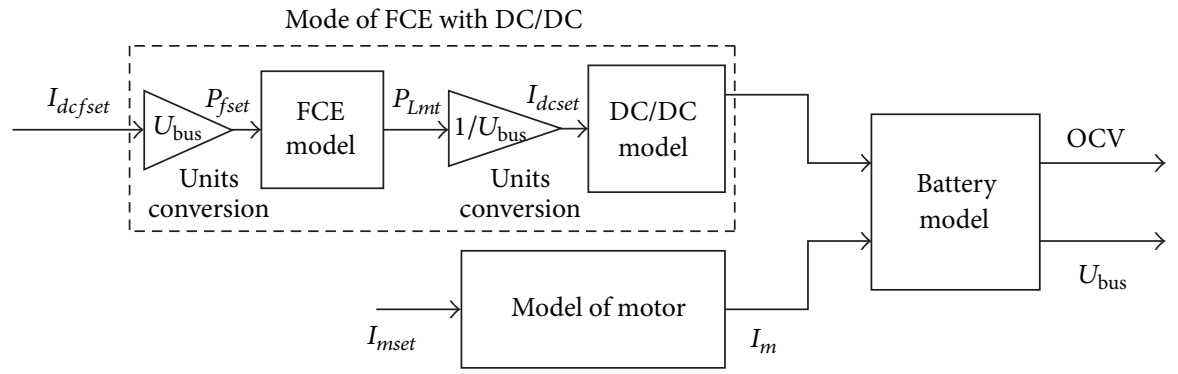

$I_{d c f s e t}$ : current setting (FCE with DC/DC); $I_{m s e t}$ : motor current setting

$P_{f s e t}:$ FCE power setting; $P_{\text {Lmt }}:$ upper limit of FCE power

$I_{m}$ : motor output current; $I_{d c f}:$ DC/DC output current

OCV: battery open circuit voltage; $U_{\text {bus }}$ : bus voltage

$I_{d c s e t}: \mathrm{DC} / \mathrm{DC}$ current setting

FIGURE 2: The block diagram of the simulation model.

$$
A=\left[\begin{array}{ccccc}
-\frac{1}{T_{f}} & 0 & 0 & 0 & 0 \\
0 & -\frac{1}{T_{m c}} & 0 & 0 & 0 \\
\frac{1}{C_{E}} & -\frac{1}{C_{E}} & 0 & 0 & 0 \\
\frac{1}{C_{1}} & -\frac{1}{C_{1}} & 0 & -\frac{1}{R_{1} C_{1}} & 0 \\
\frac{1}{C_{2}} & \frac{1}{C_{2}} & 0 & 0 & -\frac{1}{R_{2} C_{2}}
\end{array}\right],
$$

Herein, $K_{f}, T_{f}, K_{m c}, T_{m c}, C_{E}, C_{1}, C_{2}, R_{0}, R_{1}$, and $R_{2}$ are constants of the model, which can be estimated by the leastsquares parameter estimation method.
Based on the mathematic model, a simulation model is constructed. Figure 2 is the overall system model block diagram, which indicates the input and output signals of all component models and how they are interconnected.

To verify the mathematic model and simulation model of the power train, the exampled comparison between simulation results with test data is presented in Figure 3, confirming that the FCHV model can meet the demand of model-based FCHV control design.

\section{Multistate Feedback Control Strategy Designing Based on LQR}

According to state equation of the FCHV power train, the power train is marginally stable and little random interference may cause system instability. Therefore, it is very important for energy management system to maintain the power balance of the power train.

In this study, a multistate feedback control strategy is designed based on linear quadratic regulator (LQR) algorithm. A multistate feedback controller is designed using LQR technique and a Kalman filter (KF) observer is designed for battery open circuit voltage (OCV) estimation. Figure 4 shows the schematic diagram of this new control strategy, where $u_{f}$ is feedforward control input, $u_{b}$ is feedback control input, $u$ is actual input, $y$ is actual output, $x_{\text {target }}$ is target setting of the controller, and $\widehat{x}$ is the state observed by the KF observer. 


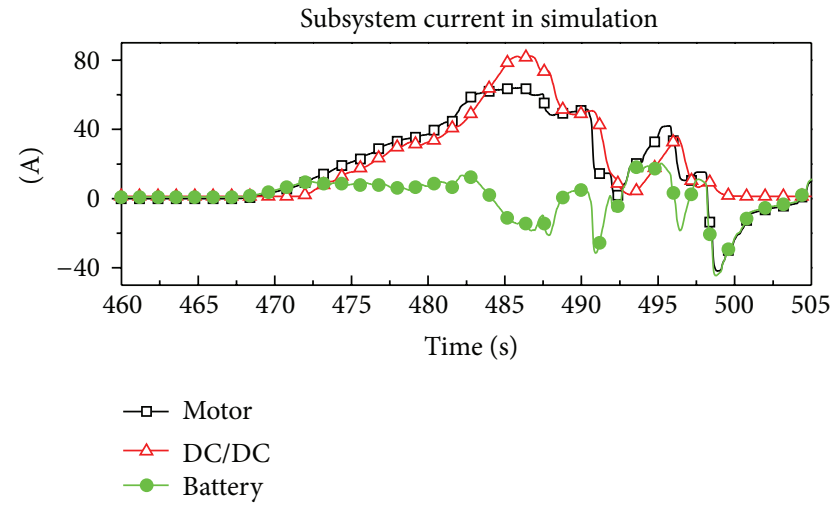

(a)

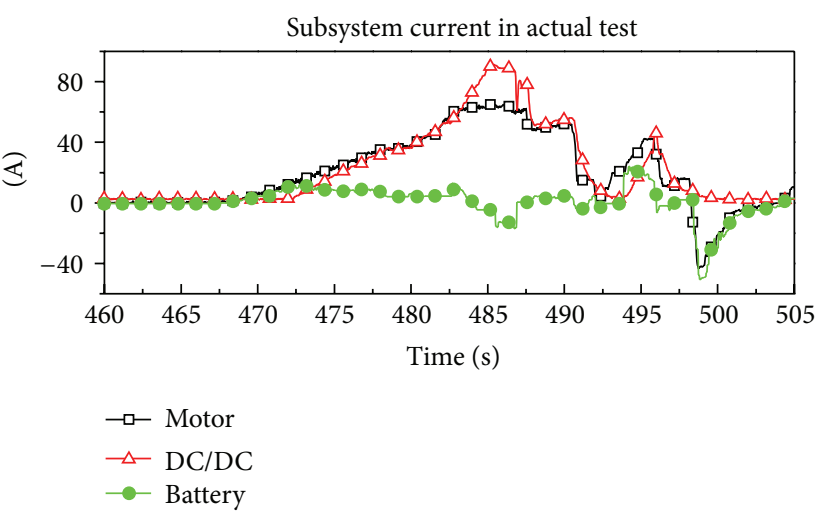

(b)

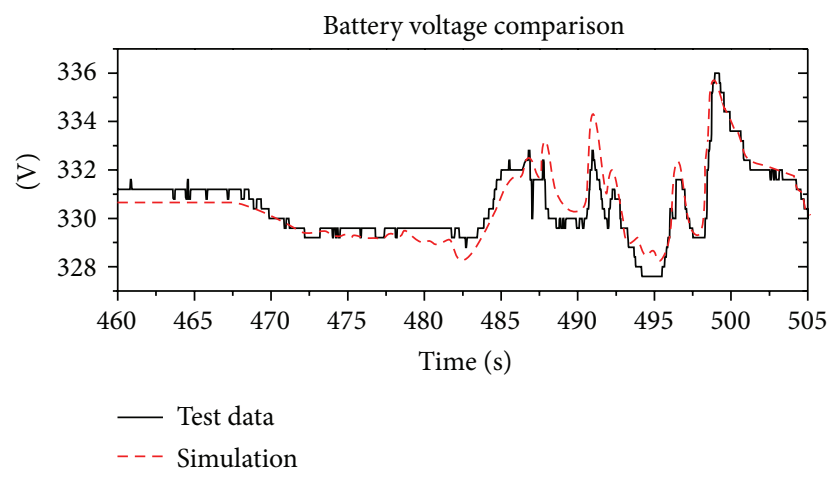

(c)

FIGURE 3: Comparison between simulation results and test data (part of J1015 cycle).

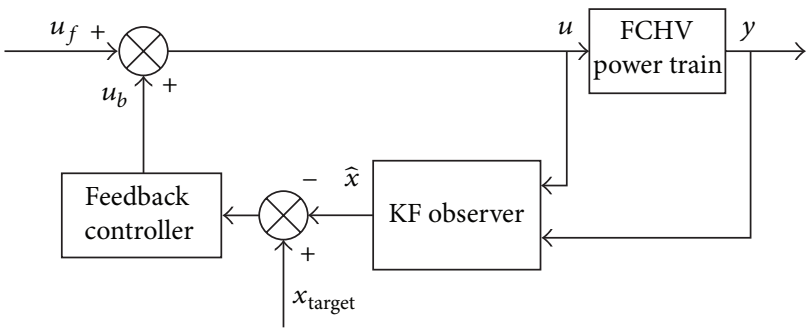

FIGURE 4: The schematic diagram of the multistate feedback control strategy.

To make the control framework more suitable for the actual control input, the control framework shown in Figure 4 is reformed, as shown in Figure 5. This control strategy can be described by

$$
\begin{aligned}
& u=u_{f}+u_{b} \\
& u_{f}=\left[\begin{array}{lll}
0 & 0 & I_{\text {mset }_{f f}}
\end{array}\right]^{T} \\
& u_{b}=\left[\begin{array}{c}
P_{f s e t} f \\
I_{\text {dcfset }_{f b}} \\
I_{\text {mset }_{f b}}
\end{array}\right]=K\left(x_{\text {target }}-\hat{x}\right)
\end{aligned}
$$

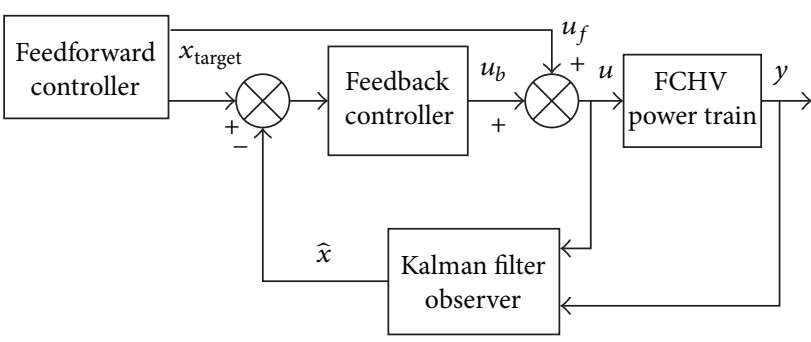

FIGURE 5: The schematic diagram of the multistate feedback strategy (reformed).

$$
\begin{aligned}
= & {\left[\begin{array}{lllll}
K_{11}^{\prime} & K_{12}^{\prime} & K_{13}^{\prime} & K_{14}^{\prime} & K_{15}^{\prime} \\
K_{21} & K_{22} & K_{23} & K_{24} & K_{25} \\
K_{31} & K_{32} & K_{33} & K_{34} & K_{35}
\end{array}\right] } \\
& \times\left(\left[\begin{array}{c}
0 \\
0 \\
\mathrm{OCV}_{\text {obj }} \\
0 \\
0
\end{array}\right]-\left[\begin{array}{c}
\widehat{I}_{d c f} \\
\widehat{I}_{m} \\
\widehat{U}_{E} \\
\widehat{U}_{1} \\
\widehat{U}_{2}
\end{array}\right]\right) \\
= & \times\left[\begin{array}{lllll}
K_{11}^{\prime} & K_{12}^{\prime} & K_{13}^{\prime} & K_{14}^{\prime} & K_{15}^{\prime}
\end{array}\right] \\
= & U_{\text {bus }}\left[\begin{array}{lllll}
K_{11} & K_{12} & K_{13} & K_{14} & K_{15}
\end{array}\right] .
\end{aligned}
$$




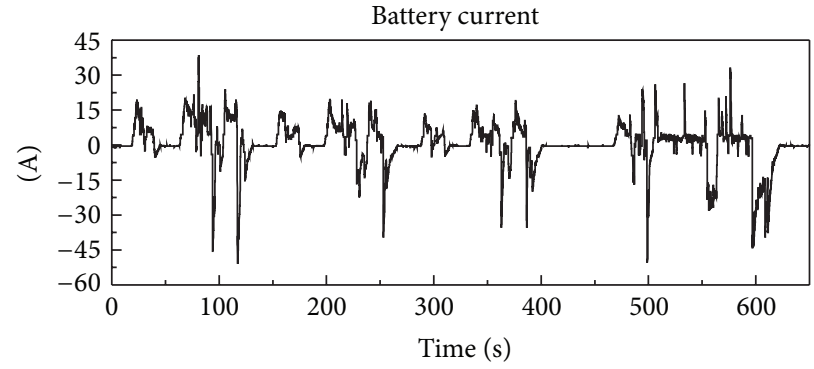

(a)

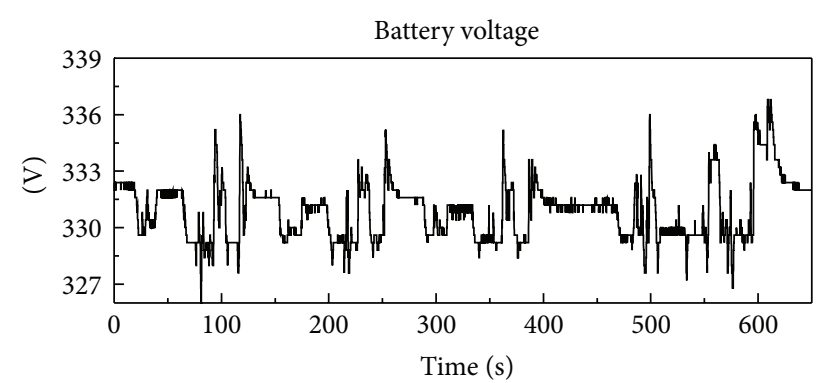

(b)

FIgURE 6: Current and voltage of the battery (J1015 cycle).

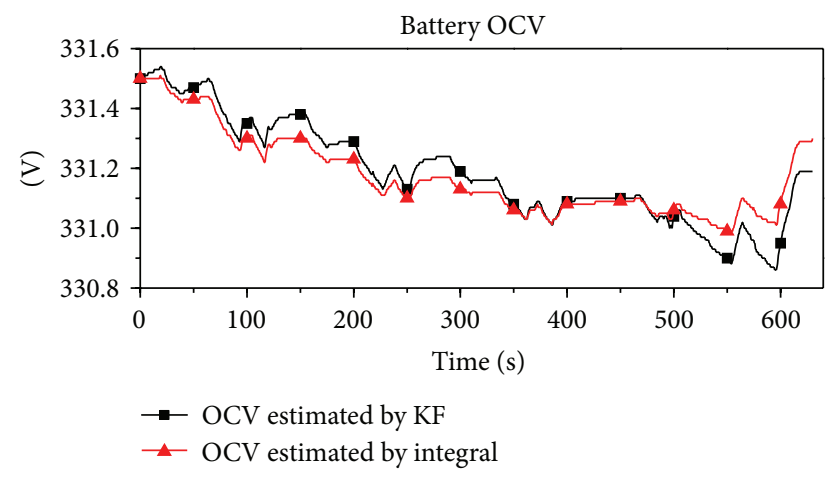

Figure 7: Battery OCV estimated by the KF observer and current integral method.

Herein, $\mathrm{OCV}_{\text {target }}$ represents the target value of the battery $\mathrm{OCV}$, and $K$ is the state feedback matrix. The variables shown in (3) have been explained in Figure 2. In the actual control system, $u_{f}$ is computed by power demand of the power train and limited by some boundary condition $u_{b}$ is computed by control deviation and the state feedback matrix $K$.

3.1. Observer Designing Based on KF. Although battery OCV is not a linear function of battery SOC, according to [16], when battery SOC is in $20 \% \sim 90 \%$ (its work range), battery OCV has a corresponding relationship with battery SOC. Therefore, the fluctuated ranges of the SOC can be regulated by changing the target value of the battery OCV OCV $\mathrm{target}_{B}$, namely, $U_{E}$ of the state-space model. However, the state $U_{E}$ is not a measurable variable in the power train. To estimate the state $U_{E}$, a KF observer is designed. The discrete statespace model of the battery can be obtained from the statespace model of the battery equation as follows:

$$
\begin{gathered}
x(k)=G x(k-1)+H u(k)+\Gamma w(k), \\
z(k)=M x(k)+N u(k)+v(k),
\end{gathered}
$$

where state vector $\mathbf{x}(\mathbf{k})=\left[\begin{array}{lll}U_{E}(k) & U_{1}(k) U_{2}(k)\end{array}\right]^{T}$, input vector $\mathbf{u}(\mathbf{k})=\left[I_{b}(k)\right]$, output vector $\mathbf{y}(\mathbf{k})=\left[U_{\text {bus }}(k)\right], \Gamma$ is the noise transfer matrix, $w(k)$ and $v(k)$ are zero-mean white
Gaussian stochastic process, and $G, H, M$, and $N$ are discrete state matrices defined as

$$
\begin{gathered}
G=\left[\begin{array}{ccc}
1 & 0 & 0 \\
0 & \frac{R_{1} C_{1}}{R_{1} C_{1}+T} & 0 \\
0 & 0 & \frac{R_{2} C_{2}}{R_{2} C_{2}+T}
\end{array}\right], \quad H=\left[\begin{array}{c}
-\frac{T}{C_{E}} \\
-\frac{T R_{1} C_{1}}{R_{1} C_{1}+T} \\
-\frac{T R_{2} C_{2}}{R_{2} C_{2}+T}
\end{array}\right], \\
M=\left[\begin{array}{lll}
1 & 1 & 1
\end{array}\right], \quad N=\left[-R_{0}\right] .
\end{gathered}
$$

Herein, $T$ is the sampling period. The filter is initialized with the best information available on the state and error covariance, and the recursive equation of the KF is summarized as follows:

Initialization:

$$
\begin{array}{ll}
\widehat{X}(0)=E[X(0)], & P(0)=E\left[X(0) X(0)^{T}\right] \\
Q=E\left[w \times w^{T}\right], & R=E\left[v \times v^{T}\right]
\end{array}
$$

Recursive Computation:

$$
\begin{aligned}
& P(k \mid k-1)=G P(k-1) G^{T}+\Gamma Q \Gamma^{T}, \\
& K_{k}=P(k \mid k-1) M^{T}\left[M P(k \mid k-1) M^{T}+R\right]^{-1} \text {, } \\
& \widehat{X}(k)=\left[I-K_{k} H\right][G \widehat{X}(k-1)+H u(k)] \\
& +K_{k} z(k)-N u(k), \\
& P(k)=\left[I-K_{k} M\right] P(k \mid k-1) \text {. }
\end{aligned}
$$

Although the hypothesis about the noise process cannot conform exactly to the fact, the result obtained from the test shows that the KF observer still performs well.

To validate the KF observer designed here, a J1015 dynamic test was performed (sample period was $50 \mathrm{~ms}$ ) As the input data of the KF observer, the current and voltage of the battery were collected in the test, as shown in Figure 6 . The estimated results of the battery OCV by the KF observer and current integral calculation method shown in Figure 7 


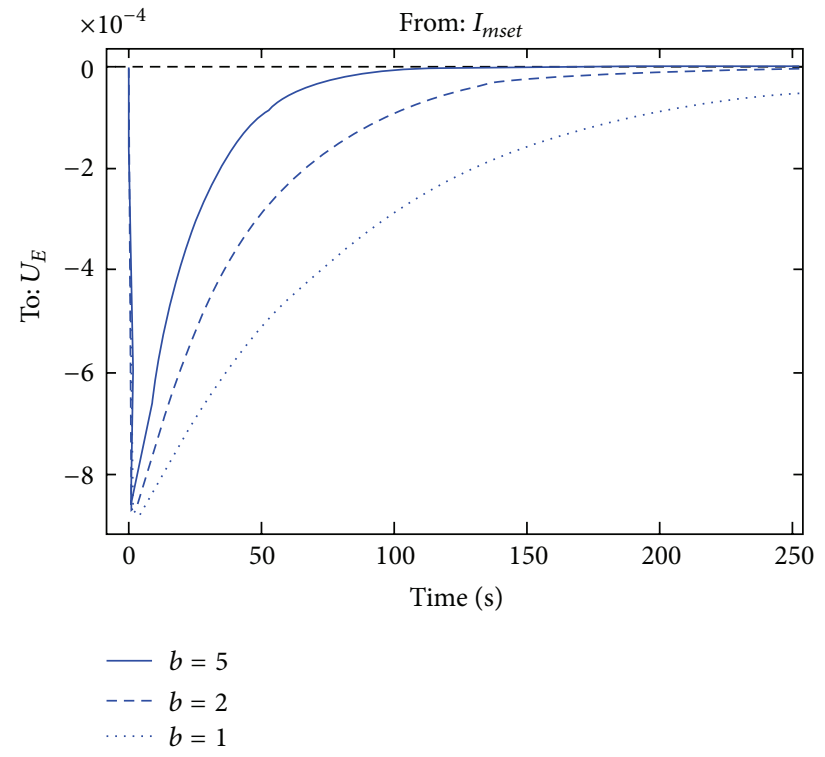

(a)

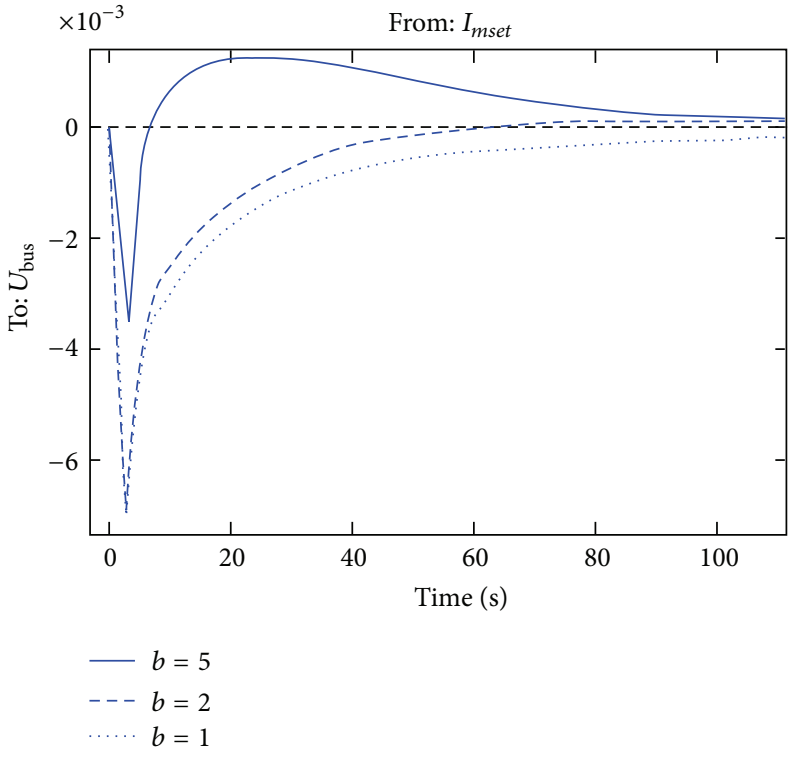

(b)

FIGURE 8: Step responding of the model.

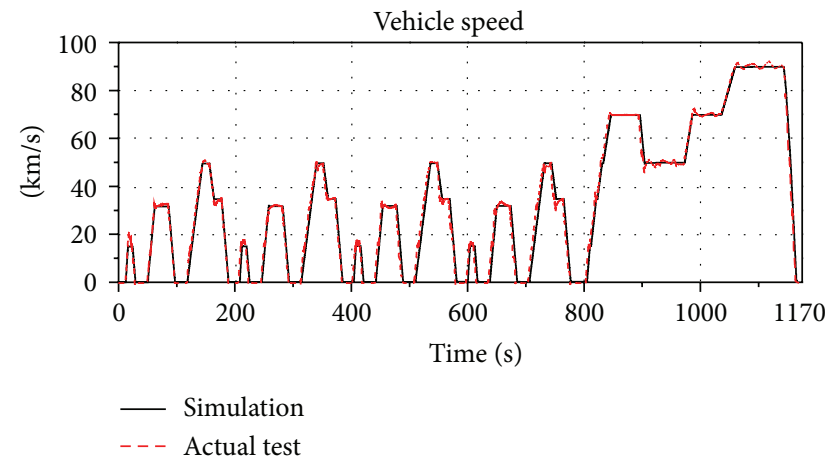

FIgUre 9: Changing process of vehicle speed (ECE_EUDC cycle).

indicate that, if the initial deviation is excluded from consideration, the maximum error is not more than $1 \%$ in the cycle test. Though the current test data has its inevitable error, in a relatively short time OCV estimated by current integral calculation approaches the actual value. Therefore, the test result indicates that the KF designed for battery OCV estimation is valid.

3.2. Multistate Feedback Controller. The state feedback matrix $K$ is very important for the multistate feedback controller. In actual control strategy, elements of the matrix $K$ need to be restrained by some limitation and boundary condition, as shown in the following:

$$
\begin{gathered}
K_{11}<m, \quad K_{13}<n, \quad K_{14}<o, \quad K_{15}<p, \\
K_{21}=K_{22}=K_{23}=K_{24}=K_{25}=0,
\end{gathered}
$$

where $m, n, o$, and $p$ are the limitations determined by configuration parameters of the power train and practical experience. $K_{11}$ is selected according to the test, $K_{13}, K_{14}$, and $K_{15}$ can be selected properly by analyzing the step responding of the model. To compute state feedback gain in an optimal way, LQR is constructed based on the linear mathematic model of the power train, and the quadratic characteristic index function of the regulator is as follows:

$$
\begin{gathered}
J=\frac{1}{2} \int_{t_{0}}^{\infty}\left[a\left(I_{d c f}-I_{m}\right)^{2}+b U_{E}^{2}+c U_{1}^{2}+d U_{2}^{2}\right. \\
\left.+e I_{d c f s e t}{ }^{2}+f I_{\text {mset }}^{2}\right] d t \\
=\frac{1}{2} \int_{t_{0}}^{\infty}\left[x^{T}(t) Q x(t)+u^{T}(t) R u(t)\right] d t .
\end{gathered}
$$

In (8), $a, b, c, d, e$, and $f$ are the weight of each item, $Q$ is the state weight matrix, and $R$ is the control weight matrix. Using Hamilton minimum principle, the state feedback matrix can be obtained by solving (8) for analytic solution. Note that the selection of proper weight matrix is very important for solving the equation. There are several helpful rules on the selection of $Q$ and $R:$ (1) $Q$ and $R$ are symmetrical matrixes, in which $Q$ is a half positive definite matrix and $R$ is a positive definite matrix; (2) because $Q$ and $R$ are interrelated, once $R$ is determined firstly, $Q$ can be determined by simulation and test. In addition, state feedback matrix is limited by the boundary conditions, namely, (7) in this paper.

In state weight matrix $Q, b$ is very important, which affects the stability of the close-loop control system directly. To make control system stable, $b$ must be properly selected to make sure that all poles of the close-loop control system are in left quadrant. In addition, it can be seen that the larger the $b$, the more stable the control system. 


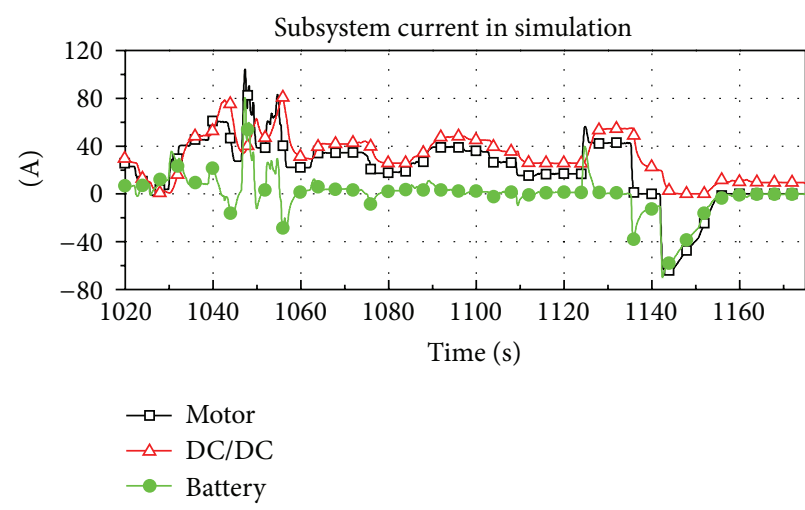

(a)

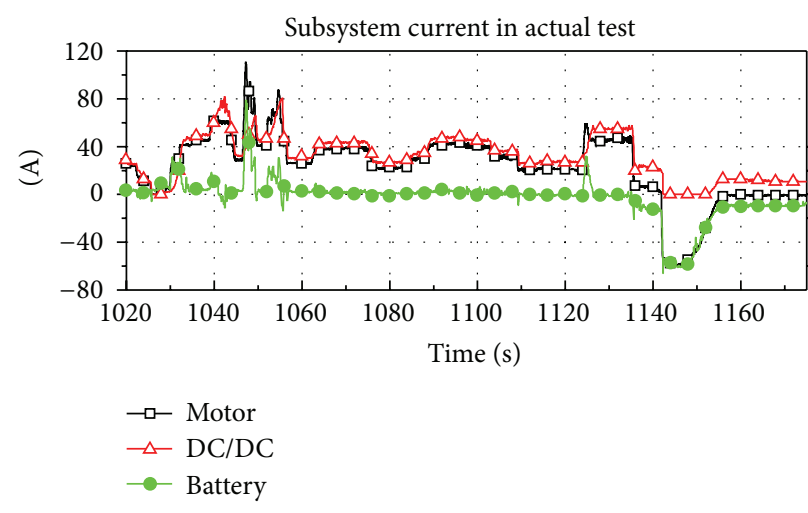

(b)

FIGURE 10: Changing process of subsystem current (part of the ECE_EUDC cycle).

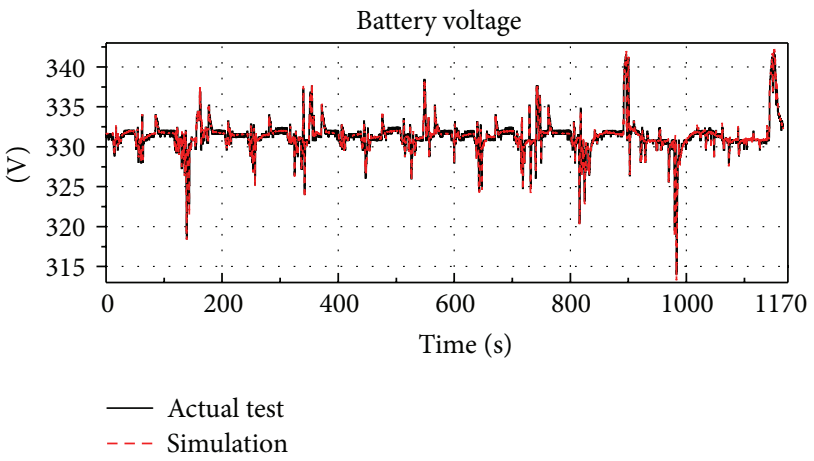

FIGURE 11: Changing process of battery voltage (ECE_EUDC cycle).

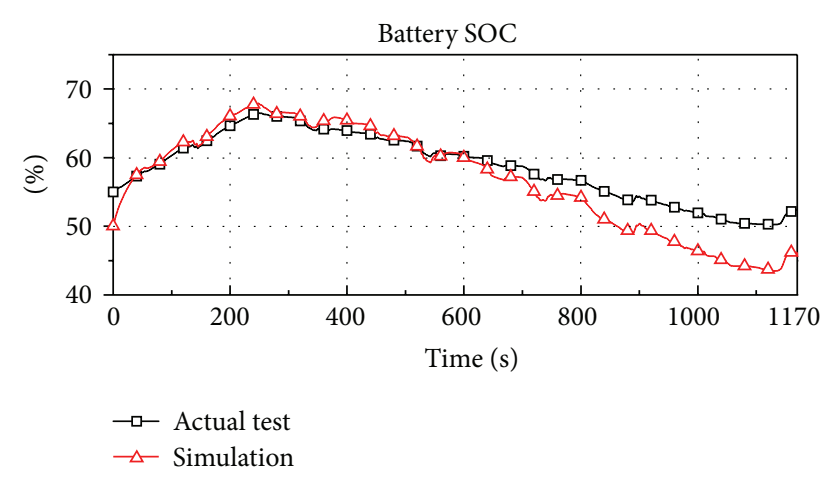

FIGURE 12: Changing process of battery SOC (ECE_EUDC cycle).

Figure 8 presents the exampled system step responding curves. It can be seen that the larger $b$ leads to the faster converging behavior of $U_{E}$. However, if $b$ is over large, $U_{\text {bus }}$ will become vibration. When $b$ equals $2, U_{E}$ and $U_{\text {bus }}$ tend to balance position with moderate speed.

\section{Verification of the Control Strategy}

Simulation and practical driving test on the designed control strategy with three driving cycles are conducted. The driving cycle includes J1015, UDDS, and NEDC. Exampled simulation and test data from NEDC driving cycle are presented in Figures 9-12. Figure 9 shows the changing process of vehicle velocity in the simulation and practical test during the NEDC cycle, indicating that the vehicle's power performance can be ensured using the designed strategy. Figure 10 shows the changing process of the subsystem current. Figure 11 shows the changing processes of the battery voltage and SOC during the NEDC driving cycle, where the battery voltage and SOC fluctuate within the prescriptive range, indicating that the proposed control strategy can guarantee the stable control of the FCHV power train.

\section{Conclusions}

In summary, a LQR-based control strategy designing method for FCHV power train is proposed in this study. A multistate feedback control strategy is designed and applied in the power train of SHANGHAI FCHV. In this control strategy, a KF observer is introduced to estimate battery OCV and the state feedback gain matrix of the multistate feedback control system is computed by the LQR algorithm. To verify the designed control strategy, simulation and practical driving test with three types of driving cycles are conducted. The results of the simulation and practical testing show that the designed LQR-based power control strategy can ensure power performance of the vehicle and guarantee the stable control of the hybrid power train, which proves that the designed control strategy works excellently.

The LQR-based control design method presented in this research well suits to control development for FCHV power train. And it provides valuable reference to the model-based control strategy development for other types of hybrid power train.

\section{Conflict of Interests}

The authors declare that there is no conflict of interests regarding the publication of this paper. 


\section{Acknowledgment}

The paper is supported by the National Natural Science Foundation of China (no. 51205215).

\section{References}

[1] H. S. Lee, K. S. Jeong, and B. S. Oh, "An experimental study of controlling strategies and drive forces for hydrogen fuel cell hybrid vehicles," International Journal of Hydrogen Energy, vol. 28, no. 2, pp. 215-222, 2003.

[2] G. Pede, A. Iacobazzi, S. Passerini, A. Bobbio, and G. Botto, "FC vehicle hybridisation: an affordable solution for an energyefficient FC powered drive train," Journal of Power Sources, vol. 125, no. 2, pp. 280-291, 2004.

[3] M. Mohammadian, S. M. T. Bathaee, and S. M. M. Ansarey, "Neuro-genetic energy management for hybrid fuel cell power train," in Proceedings of the IEEE Conference on Cybernetics and Intelligent Systems, pp. 1043-1048, Singapore, December 2004.

[4] M.-J. Kim and H. Peng, "Power management and design optimization of fuel cell/battery hybrid vehicles," Journal of Power Sources, vol. 165, no. 2, pp. 819-832, 2007.

[5] Y. Eren, O. Erdinc, H. Gorgun, M. Uzunoglu, and B. Vural, "A fuzzy logic based supervisory controller for an FC/UC hybrid vehicular power system," International Journal of Hydrogen Energy, vol. 34, no. 20, pp. 8681-8694, 2009.

[6] J. Ryu, Y. Park, and M. Sunwoo, "Electric powertrain modeling of a fuel cell hybrid electric vehicle and development of a power distribution algorithm based on driving mode recognition," Journal of Power Sources, vol. 195, no. 17, pp. 5735-5748, 2010.

[7] J. P. Torreglosa, F. Jurado, P. García, and L. M. Fernández, "Hybrid fuel cell and battery tramway control based on an equivalent consumption minimization strategy," Control Engineering Practice, vol. 19, no. 10, pp. 1182-1194, 2011.

[8] K. Isamu, "Electric power control of fuel cell vehicle," European Patent WO2008004564, January 2008.

[9] U. S. Kwon, S. I. Jeon et al., "Method for controlling fuel cell vehicle," US Patent Application 20090222157, September 2009.

[10] U. Limbeck, S. Schmalzriedt et al., "Method and control unit for automatic selection of an operating mode for a vehicle with fuel cells," US Patent Application 20110196554, August 2011.

[11] J. T. Pukrushpan, H. Peng, and A. G. Stefanopoulou, "Simulation and analysis of transient fuel cell system performance based on a dynamic reactant flow model," in Proceedings of the ASME International Mechanical Engineering Congress and Exposition (IMECE '02), pp. 637-648, November 2002.

[12] S. Jemeï, D. Hissel, M. C. Péra, and J. M. Kauffmann, "On-board fuel cell power supply modeling on the basis of neural network methodology," Journal of Power Sources, vol. 124, no. 2, pp. 479486, 2003.

[13] C. N. Maxoulis, D. N. Tsinoglou, and G. C. Koltsakis, "Modeling of automotive fuel cell operation in driving cycles," Energy Conversion and Management, vol. 45, no. 4, pp. 559-573, 2004.

[14] M. Joong Kim, H. Peng, C. Chiao et al., "Testing, modeling, and control of a fuel cell Hybrid Vehicle," in Proceedings of the American Control Conference, pp. 3859-3864, 2005.

[15] H. Yun, Y. Zhao, and J. Wang, "Modeling and simulation of fuel cell hybrid vehicles," International Journal of Automotive Technology, vol. 11, no. 2, pp. 223-228, 2010.

[16] H. Dai, Z. Sun, and X. Wei, "Online SOC estimation of highpower lithium-ion batteries used on HEVs," in Proceedings of the IEEE International Conference on Vehicular Electronics and Safety (ICVES '06), pp. 342-347, Shanghai, China, December 2006. 


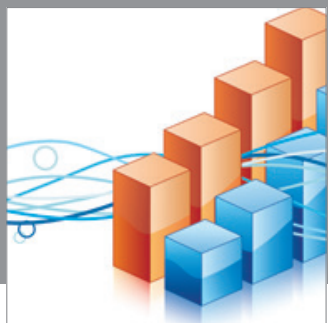

Advances in

Operations Research

mansans

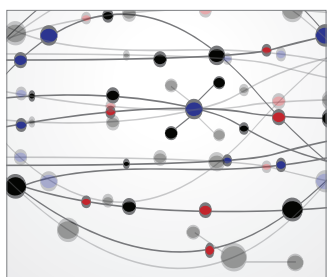

The Scientific World Journal
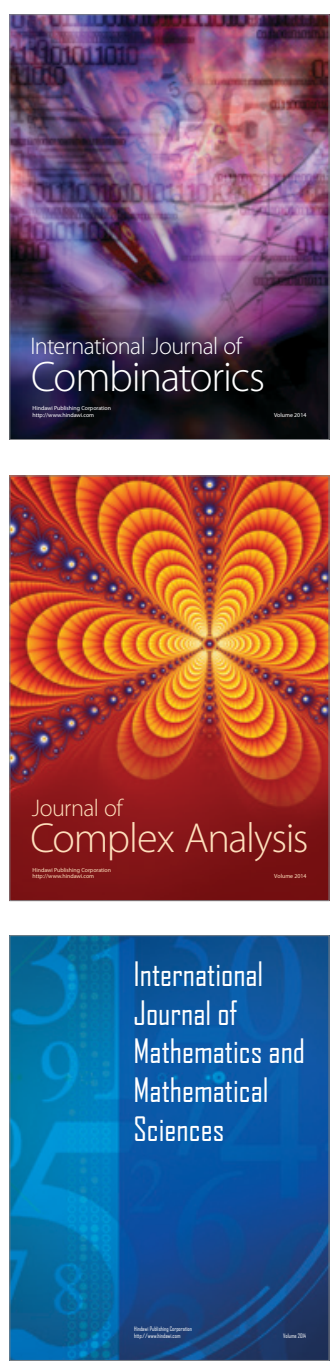
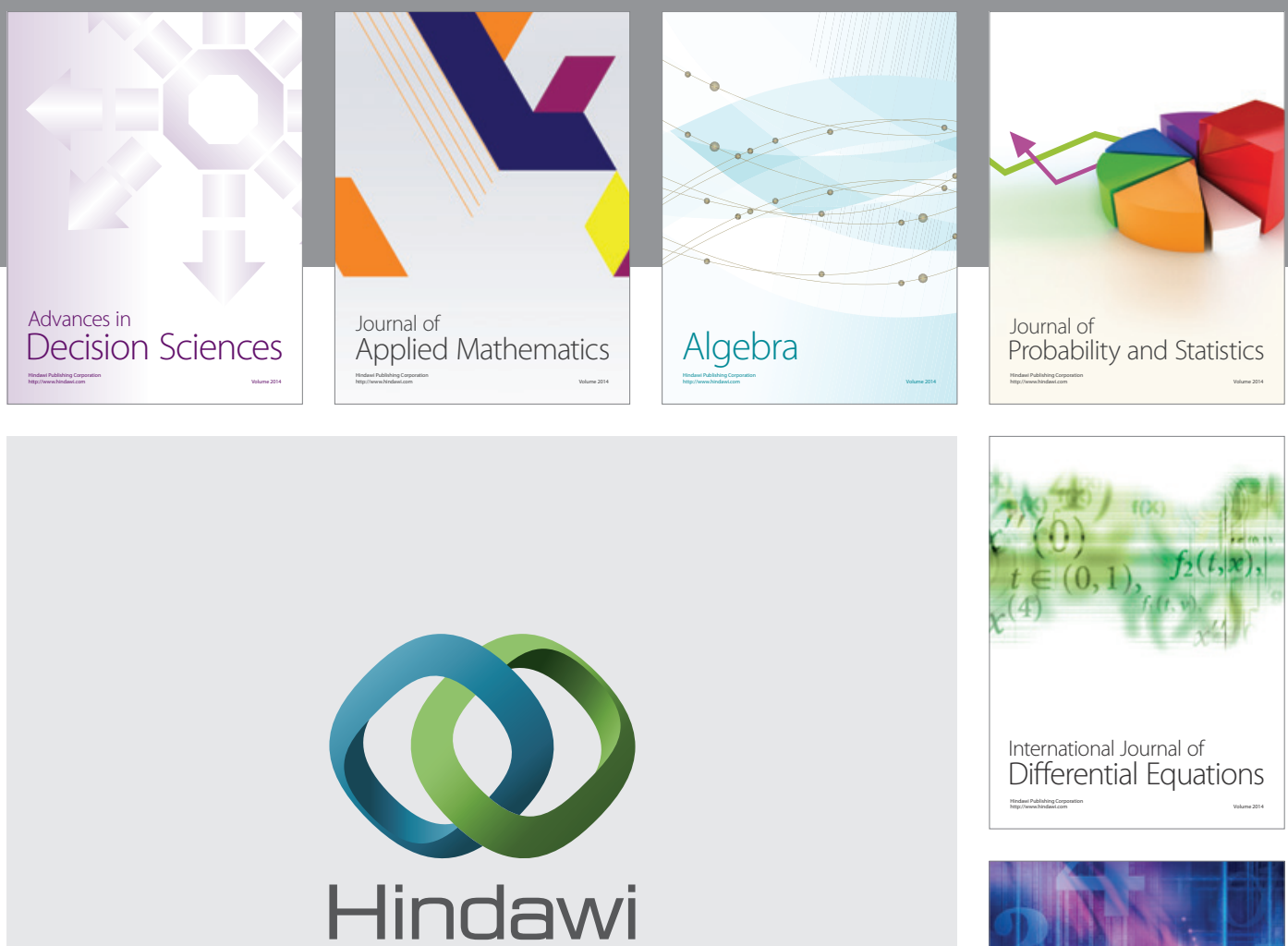

Submit your manuscripts at http://www.hindawi.com
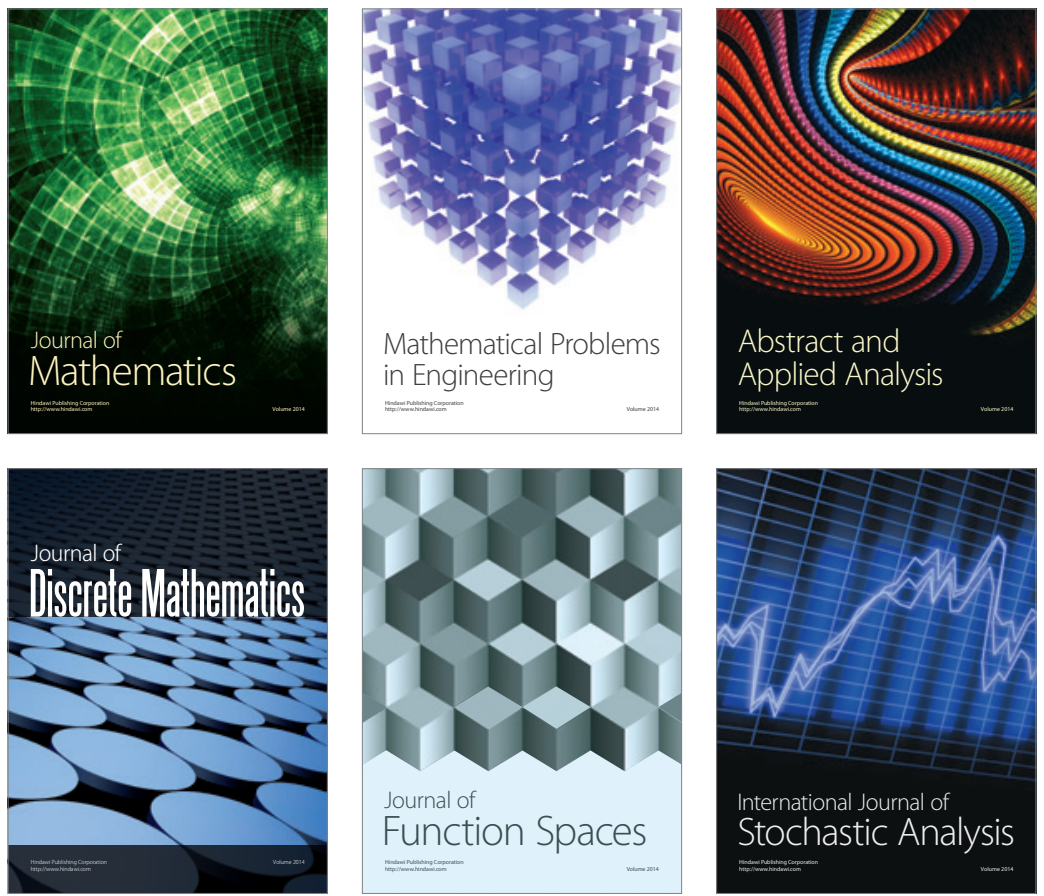

Journal of

Function Spaces

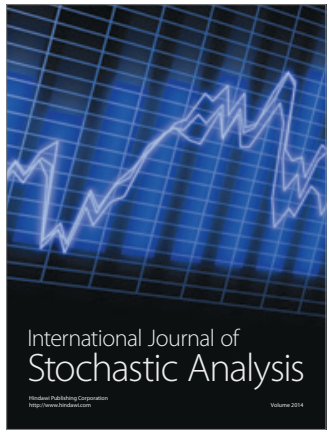

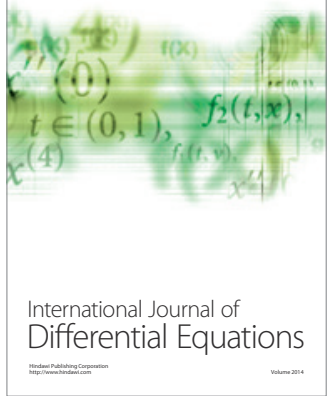
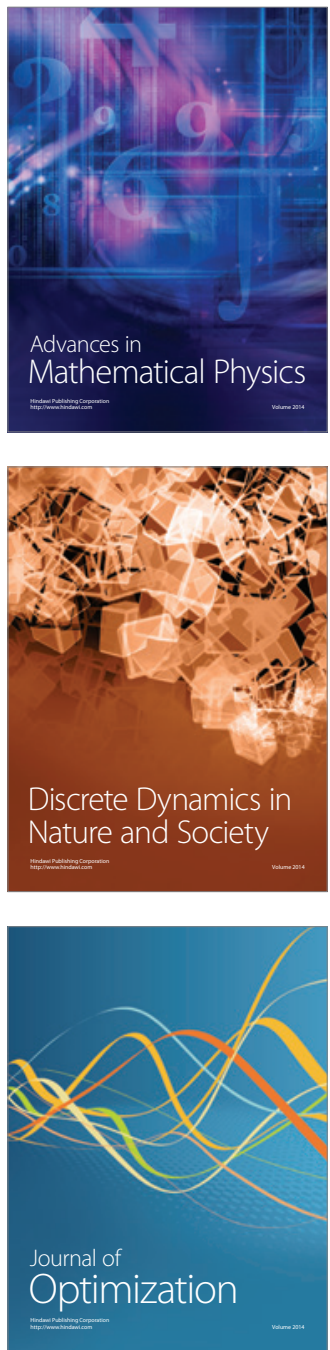